\section{Aprendizaje de una simulación: paciente COVID-19 positivo para cirugía de urgencia}

\author{
Learning from a simulation: \\ Patient COVID-19 positive for emergency surgery
}

Dr. Rodrigo Rubio-Martínez,* Dr. Alejandro Eduardo Díaz-Hernández,
Dra. Roxana Trejo-González, ${ }^{\S}$ Dr. J Sebastián Espino-Núñez

RESUMEN. Se realizó una simulación in situ del proceso de atención de paciente con diagnóstico de COVID-19 programado para una cirugía de urgencia. Se observó desde la llegada al Departamento de Urgencias y hasta su salida del quirófano. Se llevaron a cabo los protocolos previamente establecidos y se observó por áreas de oportunidad.

ABSTRACT. An in situ simulation was performed of a patient with COVID-19 diagnosis that is schedule for emergency surgery. From the arrival to the Emergency Department to the exit from the operating theatre. Previously stablished protocols were performed, and areas of improvement were looked for.

Abreviaturas:

$\mathrm{EPP}=$ Equipo de protección personal.

PCR = Reacción en cadena de la polimerasa.

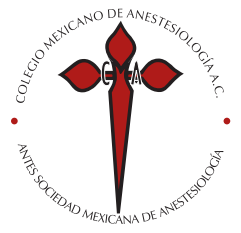

Palabras clave: COVID-19, debriefing, in situ.

Keywords:

COVID-19, debriefing, in situ.

\footnotetext{
* Presidente de la Práctica Médica Grupal de Anestesiología del Centro Médico ABC.

‡ Jefe de Quirófano del Centro Médico ABC Campus Santa Fe.

$\S$ Jefa de Epidemiología del Centro Médico ABC Campus Santa Fe.

\| Departamento de Anestesiología, Centro Médico ABC.
}

\section{Solicitud de sobretiros: Dr. Rodrigo Rubio-Martínez Centro Médico ABC Campus Observatorio. Sur 136 Núm. 116, Col. Las Américas, Álvaro Obregón, 01120, Ciudad de México. Tel: 5230-8000 \\ E-mail: rodrigorubio@mac.com \\ Recibido para publicación: 07-04-2020 \\ Aceptado para publicación: 15-04-2020}

\section{INTRODUCCIÓN}

L a propagación del virus SARS-Cov2 a nivel mundial no $\longrightarrow$ ha tenido precedentes. Conforme se observan las experiencias en otro países del mundo, la preparación institucional es un imperativo ético para preservar la vida de pacientes y personal de salud por igual ${ }^{(1,2)}$. Para esto, la simulación tiene un rol relevante en la preparación y control de adecuados estándares para los cuidadores y los pacientes ${ }^{(3)}$.

La fuente de mayor carga viral son las secreciones de las vías aéreas superiores ${ }^{(4,5)}$. Por esa razón la anestesiología se ha descrito como una de las especialidades con mayor riesgo de exposición por la generación de aerosoles y contacto con fluidos respiratorios durante los procedimientos ${ }^{(6)}$. Todos aquellos presentes en el espacio físico donde se realiza una intervención de la vía aérea podrían estar en riesgo de contagio por la generación de aerosoles ${ }^{(7)}$. Por eso es imperativo que el paciente sometido a cirugía con el diagnóstico de COVID-19 sea atendido por un equipo multidisciplinario entrenado en la adecuada utilización del equipo de protección personal $(\mathrm{EPP})^{(8)}$.

Mientras que la atención de pacientes con enfermedad COVID-19 es una prioridad, la presentación de otros padecimientos médico-quirúrgicos no altera su incidencia ${ }^{(9,10)}$. Esto significa una carga de trabajo para los hospitales y su personal mayor a la habitual. Y la posibilidad, con un aumento de la prevalencia de casos positivos, que la enfermedad respiratoria coexista con otro padecimiento.

La simulación in situ se refiere a aquella realizada en el espacio clínico real y no en un centro de simulación ${ }^{(11)}$. Ésta se puede realizar con maniquíes pero también se puede realizar con un actor como paciente estandarizado y tiene el objetivo de analizar el sistema, no a las personas. Nos ayuda a identificar en dónde nuestro sistema se encuentra fortalecido y también 
espacios o momentos en donde existan brechas de seguridad para el paciente o los trabajadores de la salud ${ }^{(12,13)}$.

\section{MATERIAL Y MÉTODOS}

Se realizó una simulación in situ de presentación de un paciente con diagnóstico COVID-19 y un padecimiento quirúrgico que amerita cirugía de urgencia.

El objetivo fue observar y documentar el proceso completo de atención de paciente COVID-19 positivo, identificando momentos críticos, fortalezas y debilidades del sistema, así como áreas de riesgo y contaminación para el personal de salud ante los protocolos institucionales previamente establecidos. Como objetivo secundario se tuvo el diseño de recomendaciones de mejora al proceso con base en lo observado.

Personal que participó en la simulación pertenece a las áreas de Urgencias (médico adscrito y residente, enfermería, admisión, medio ambiente y camillería), y de quirófano (cirujano general, cirujano ortopedista, anestesiólogo, residentes de las tres especialidades, enfermería, ingeniería biomédica, CEYE, suministros y camillería). Los observadores de la simulación fueron el Dr. Hernández-Díaz, jefe de quirófano de Campus Santa Fe, la Dra. Trejo-González jefa de epidemiología y el Dr. Rubio-Martínez presidente de la práctica médica grupal de anestesiología y experto en simulación clínica.

El planteamiento del caso fue el siguiente: paciente masculino de 30 años de edad con diagnóstico de COVID-19 confirmado por PCR en tratamiento ambulatorio por sintomatología leve, quien al realizar labores de mantenimiento en hogar sufre caída de cinco metros de altura, con fractura expuesta de cúbito derecho Gustilo-Anderson II y abdomen agudo. Se programa para laparoscopía exploratoria con probable laparotomía más lavado quirúrgico y fijación de fractura expuesta de cúbito.

\section{RESULTADOS}

Se realizaron dos debriefings de la simulación. El primero se realizó con todo el personal operativo que participó bajo la metodología plus/delta y retroalimentación dirigida ${ }^{(14)}$. El segundo se realizó únicamente entre los observadores.

Una primera fase consistió en la expresión de los participantes de su estado emocional ante la simulación. La expresión más repetida fue confusión y temor. Ambas derivadas del desconocimiento rutinario de las técnicas para mantenerse seguro. Sin embargo, se compartieron emociones como trabajo en equipo, orgullo, seguridad y entusiasmo, derivadas del cuidado mutuo y el interés común por el paciente. Al incluir al actor de paciente en el debriefing se comentó una sensación de ser «no querido» y de generarle ansiedad al personal que le brindó atención.
Se identificaron los siguientes aspectos positivos:

- Adecuada infraestructura.

- Kits de EPP son adecuados.

- Se detectó el riesgo desde el proceso de admisión.

- Disposición y trabajo en equipo de los involucrados.

- Cuidado mutuo entre los profesionales de la salud en un ambiente cordial.

Se concluyeron las siguientes recomendaciones:

- Los residentes no deben valorar pacientes en urgencias ya que consume EPP, el interrogatorio se realizará de forma indirecta y la valoración de vía aérea se realizará en quirófano.

- La valoración de anestesiología se puede hacer con interrogatorio indirecto.

- Las firmas de consentimientos informados se recaban en un solo momento.

- El expediente, al ser una extensión del paciente, podría considerarse contaminado.

- Se debe realizar un briefing con todo el personal que estará involucrado para compartir modelos mentales y el plan general.

- El paciente no se solicita en quirófano hasta que todo se confirme listo.

- Al solicitar al paciente del Departamento de Urgencias, el camillero ya está disponible en el transfer.

- El paciente no sale de su cubículo en urgencias hasta que el elevador esté listo.

- El traslado de paciente incluye personal de medio ambiente que deberá limpiar el elevador y los botones.

- Ingeniería biomédica será responsable de comprobar la máquina de anestesia, colocar la bolsa y también cables y circuito anestésico.

- Anestesiología deberá hacer revisión secundaria del equipo previo a tener contacto con el paciente.

- Colocar avisos en los vestidores para que el personal médico no ingrese con artículos personales o joyería.

- Al término de la cirugía, la circulante externa debe utilizar una lista de verificación para el proceso de retiro de EPP.

\section{DISCUSIÓN}

La simulación tiene un rol significativo para muchos propósitos en la industria de la salud. La reflexión compartida de los equipos que se dedican a brindar atención a pacientes es uno de los frutos más significativos de la simulación en el centro de trabajo ${ }^{(15)}$.

Por nuestra profesión estamos en mayor riesgo de contagio por este nuevo virus. La intubación y en general las técnicas de manipulación de la vía aérea se asocian a un riesgo eleva- 
do de transmisión. Es por eso que han surgido protocolos y recomendaciones para disminuir el riesgo aunque todas ellas con bajos niveles de evidencia ${ }^{(12,15,16)}$.

Debemos exigir la disponibilidad de equipo de protección personal en suficiencia, y también del uso de la simulación para prepararnos como equipo y como individuos para disminuir nuestro riesgo de exposición.

Estamos conscientes de que la realidad de nuestro centro médico puede no ser compartida con muchos otros de nuestro país, incluso existen variaciones entre nuestros campus. Sin embargo, el presente artículo tiene como propósito establecer un marco de referencia para que cada institución realice ejercicios similares para identificar áreas de mejora de sus propios protocolos.

\section{CONCLUSIONES}

La situación que estamos viviendo frente al COVID-19 ha propuesto cambios en las formas en las que normalmente hacemos las cosas. La simulación debe utilizarse en la etapa de preparación para garantizar que las habilidades técnicas y no técnicas estén a la altura del reto que esta crisis significa para todos los que trabajamos en el área de la salud.

La simulación in situ no requiere de tecnología y puede aportar información muy valiosa que en el caso real ayudará a disminuir el error. No podemos hacer humanos a prueba de errores, pero sí podemos diseñar sistemas que disminuyan el error. Realizar una simulación in situ nos dará información suficiente para hacer cambios en el sistema que disminuyan el error.

\section{REFERENCIAS}

1. Wu Z, McGoogan JM. Characteristics of and important lessons from the coronavirus disease 2019 (COVID-19) outbreak in china: summary of a report of 72314 cases from the Chinese center for disease control and prevention. JAMA. 2020 Feb 24. doi: 10.1001/ jama.2020.2648.

2. Wax RS, Christian MD. Practical recommendations for critical care and anesthesiology teams caring for novel coronavirus (2019-nCoV) patients. Can J Anaesth. 2020. doi: 10.1007/s12630-020-01591-x.

3. Schmidt E, Goldhaber-Fiebert SN, Ho LA, McDonald KM. Simulation exercises as a patient safety strategy: a systematic review. Ann Intern Med. 2013;158:426-432.

4. Wang W, Xu Y, Gao R, Lu R, Han K, Wu G, et al. Detection of SARSCoV-2 in different types of clinical specimens. JAMA. 2020 Mar 11. doi: 10.1001/jama.2020.3786.

5. Pan Y, Zhang D, Yang P, Poon LLM, Wang Q. Viral load of SARS-CoV-2 in clinical samples. Lancet Infect Dis. 2020;20:411-412.

6. Tran K, Cimon K, Severn M, Pessoa-Silva CL, Conly J. Aerosol generating procedures and risk of transmission of acute respiratory infections to healthcare workers: a systematic review. PLoS One. 2012;7:e35797.

7. Brat GA, Hersey SP, Chhabra K, Gupta A, Scott J. Protecting surgical teams during the COVID-19 outbreak: a narrative review and clinical considerations. Ann Surg. 2020.

8. Cook TM. Personal protective equipment during the COVID-19 pandemic - a narrative review. Anaesthesia. 2020 Apr 4. doi: 10.1111/ anae.15071.
9. Emanuel EJ, Persad G, Upshur R, Thome B, Parker M, Glickman A, et al. Fair allocation of scarce medical resources in the time of Covid-19. N Engl J Med. 2020 Mar 23. doi: 10.1056/NEJMsb2005114.

10. Brindle M, Gawande A. Managing COVID-19 in surgical systems. Ann Surg. 2020 Mar 23. doi: 10.1097/SLA.0000000000003923.

11. Kurup V, Matei V, Ray J. Role of in situ simulation for training in healthcare: opportunities and challenges. Curr Opin Anaesthesiol. 2017;30:755-760.

12. Owei L, Neylan CJ, Rao R, Caskey RC, Morris JB, Sensenig R, et al. In situ operating room-based simulation: a review. J Surg Educ. 2017;74:579-588.

13. Fregene TE, Nadarajah P, Buckley JF, Bigham S, Nangalia V. Use of in situ simulation to evaluate the operational readiness of a highconsequence infectious disease intensive care unit. Anaesthesia. 2020 Mar 27. doi: 10.1111/anae.15048.

14. Sawyer T, Eppich W, Brett-Fleegler M, Grant V, Cheng A. More than one way to debrief: a critical review of healthcare simulation debriefing methods. Simul Healthc. 2016;11:209-217.

15. Schmutz JB, Eppich WJ. Promoting learning and patient care through shared reflection: A conceptual framework for team reflexivity in health care. Acad Med. 2017;92:1555-1563.

16. Cook TM, El-Boghdadly K, McGuire B, McNarry AF, Patel A, Higgs A. Consensus guidelines for managing the airway in patients with COVID-19: Guidelines from the Difficult Airway Society, the Association of Anaesthetists the Intensive Care Society, the Faculty of Intensive Care Medicine and the Royal College of Anaesthetists. Anaesthesia. 2020. doi: 10.1111/anae.15054. 